Artículo científico

Volumen 32(3):869-887. Septiembre-diciembre, 2021 e-ISSN 2215-3608, doi:10.15517/am.v32i3.44020

https://revistas.ucr.ac.cr/index.php/agromeso/index

\title{
Compatibilidad Quitosano-Bradyrhizobium aplicados a semillas y su efecto en el desarrollo vegetativo de soya (Glycine $\max (\mathrm{L} \text {.) Merrill })^{1}$
}

\section{Chitosan-Bradyrhizobium compatibility applied to seeds and its effect in the vegetative development of soybean (Glycine max (L.) Merrill)}

\author{
Daimy Costales-Menéndez ${ }^{2}$, María Caridad Nápoles-García ${ }^{2}$,Lisbel Travieso-Hernández $z^{2}$,Omar Cartaya-Rubio², \\ Alejandro Bernardo Falcón-Rodríguez ${ }^{2}$
}

1 Recepción: 5 de octubre, 2020. Aceptación: 17 de febrero, 2021. Este trabajo formó parte de una tesis del programa de doctorado "Producción Agrícola Sostenible” del Instituto Nacional de Ciencias Agrícolas, Mayabeque, Cuba. La investigación se concibió dentro del proyecto "Desarrollo de bioestimuladores nacionales para la protección y el beneficio de cultivos de interés económico", financiado entre el 2014 y 2018 por el Programa de Alimento Humano (P131LH001160) del Ministerio de Agricultura de Cuba.

2 Instituto Nacional de Ciencias Agrícolas (INCA), Dpto. de Fisiología y Bioquímica Vegetal, Gaveta postal No.1, San José de las Lajas, Mayabeque, Cuba. CP 32700. daimy@inca.edu.cu (autor para la correspondencia, http://orcid.org/0000-0003-0121-6287); tere@inca.edu. cu (http://orcid.org/0000-0003-1413-1717); lili@inca.edu.cu (http://orcid.org/0000-0002-0312-6915); ocartaya@inca.edu.cu (http://orcid. org/0000-0001-7436-0437); alfalcon@inca.edu.cu (http://orcid.org/0000-0002-6499-1902).

\section{Resumen}

Introducción. El quitosano y las rizobacterias promotoras del crecimiento vegetal son reconocidos bioestimulantes agrícolas por los beneficios biológicos que aportan a las plantas. Objetivo. Evaluar la aplicación conjunta de concentraciones de quitosano y el inoculante Azofert-S® sobre semillas de soya, en la supervivencia de Bradyrhizobium elkanii y el desarrollo vegetativo de las plantas. Materiales y métodos. La investigación se desarrolló en el cuarto de crecimiento de plantas del Departamento de Fisiología y Bioquímica Vegetal del Instituto Nacional de Ciencias Agrícolas de Cuba, en el año 2016. Se determinó el efecto del quitosano y el inoculante Azofert-S® aplicados a semillas de soya, en el número de bacterias viables en las semillas y en el comportamiento de indicadores morfoagronómicos y fisio-bioquímicos relacionados con la nodulación y el desarrollo vegetativo de las plantas. Resultados. Las concentraciones de quitosano evaluadas en el ensayo de compatibilidad no afectaron el número de células viables en las semillas, excepto 500 y $1000 \mathrm{mg} \mathrm{l}^{-1}$, que mejoraron la supervivencia de la bacteria al comienzo del ensayo y $500 \mathrm{mg} \mathrm{l}^{-1}$ a los diez días de almacenamiento de las semillas. Esta última concentración benefició también la longitud radical y del tallo, el área foliar y la actividad enzimática de la nitrato reductasa en hojas. La aplicación combinada de Azofert ${ }^{\circledR}$ - quitosano y la sola inoculación de las semillas incrementó la concentración de nitrógeno y otros nutrientes en nódulos y trifoliolos. La concentración de flavonoides y de fenoles totales aumentó con la concentración de $10 \mathrm{mg} \mathrm{l}^{-1}$ de quitosano, aunque redujo la concentración de carbohidratos solubles totales y reductores en las hojas. Conclusión. Los bioestimulantes resultaron compatibles cuando se aplicaron sobre semillas en el momento de la siembra y beneficiaron la nodulación, la nutrición y el desarrollo vegetativo de las plantas de soya, en dependencia de la concentración del polímero.

Palabras clave: bioestimulantes, crecimiento vegetativo, nitrato reductasa, nutrientes, metabolito secundario. 


\begin{abstract}
Introduction. Chitosan and plant growth promoting rhizobacteria are recognized as agricultural biostimulants for the biological benefits they provide to plants. Objective. To evaluate the combined application of chitosan concentrations and the Azofert-S® inoculant on soybean seeds, on the survival of Bradyrhizobium elkanii and the vegetative growth of the plants. Materials and methods. The research was developed in the plant growth room of Plant Physiology and Biochemistry Department of the Instituto Nacional de Ciencias Agricolas, Cuba, in 2016. The effect of chitosan and Azofert-S® inoculant applied to soybean seeds was determined on the number of viable bacteria in seeds and the behavior of morphoagronomic and physio-biochemical indicators related to the nodulation and vegetative development of plants. Results. The chitosan concentrations evaluated in the compatibility test did not affect the number of viable cells in the seeds, except for 500 and $1000 \mathrm{mg} \mathrm{l}^{-1}$, which improved the bacteria survival at the beginning of the test and $500 \mathrm{mg} \mathrm{l}^{-1}$ at ten days of seed storage. The latter concentration also benefited root and stem length, leaf area, and nitrate reductase enzymatic activity in leaves. The combined application of Azofert ${ }^{\circledR}$ - chitosan and seed inoculation alone enhanced the concentration of nitrogen and other nutrients in nodules and trifoliolus. The concentration of flavonoids and total phenols increased with the concentration of $10 \mathrm{mg}^{1-1}$ of chitosan, although it decreased the concentration of total soluble and reductive carbohydrates in leaves. Conclusion. The biostimulants were compatible when applied on seeds at the time of sowing and benefited the nodulation, nutrition, and vegetative development of soybeans plants, depending on the concentration of the polymer.
\end{abstract}

Keywords: biostimulants, vegetative growth, nitrate reductase, nutrients, secondary metabolite.

\title{
Introducción
}

Las bacterias del género Bradyrhizobium, son capaces de realizar la fijación biológica del nitrógeno (FBN) cuando establecen simbiosis con las plantas de soya (Glycine max (L.) Merrill) y forman nódulos donde fijan el dinitrógeno (Sanches-Santos et al., 2019). Esto permite, en la práctica, desarrollar y comercializar inoculantes con cepas seleccionadas de rizobios.

Los inoculantes constituyen una excelente alternativa como bioestimulantes microbianos, porque promueven y benefician el crecimiento de las plantas mediante la incorporación de algunos nutrientes, fitohormonas y reducen los costos del uso de la fertilización nitrogenada en los cultivos (Rouphael \& Colla, 2020). El inoculante comercial cubano Azofert-S ${ }^{\circledR}$, compuesto por células de B. elkanii, incrementa el rendimiento de la soya en un $12 \%$ (Martínez et al., 2017).

El quitosano comprende un grupo de heteropolisacáridos formados por residuos de D-glucosamina y $\mathrm{N}$-acetil glucosamina, unidos por enlaces $\beta$ 1-4 (Morin-Crini et al., 2019), constituye el principal derivado del polímero natural conocido como quitina. Los quitosacáridos (polímeros y oligosacáridos de quitosano de forma parcial $\mathrm{N}$-acetilados) poseen propiedades biológicas que los hacen atractivos para su uso en la agricultura y son, en la actualidad, reconocidos bioestimulantes agrícolas (Rouphael \& Colla, 2020).

Los quitosacáridos ejercen un efecto inhibitorio en el crecimiento, el desarrollo y la reproducción de una gran variedad de microorganismos, que incluyen hongos, oomycetes y bacterias (Hu \& Gänzle, 2018; MukhtarAhmed et al., 2020; Sharif et al., 2018). La eficacia antibacteriana del quitosano ha sido mayor en las bacterias Gram positivas que en las Gram negativas, como consecuencia de diferencias en la estructura de la superficie celular y la composición de la pared celular (Badawy \& Rabea, 2011; Xing et al., 2015). De esta forma, es posible esperar una mayor resistencia en las bacterias del grupo de los rizobios, que son Gram negativas, a determinadas concentraciones de quitosano. 
La forma de aplicación y la concentración de quitosano, así como otros factores físico-químicos del polímero, como el grado de acetilación, la masa molar y la especie vegetal o el microorganismo que se trate con este compuesto (Sahariah \& Másson, 2017; Yin et al., 2016), son de relevancia en la estimulación del crecimiento y el rendimiento de las plantas (Hussain et al., 2019; Mondal et al., 2013; Morin-Crini et al., 2019; Mukhtar-Ahmed et al., 2020).

El tratamiento de semillas de soya (Glycine max) con quitosano, ha mostrado efectos significativos en la germinación y calidad de las semillas, en el crecimiento, los rendimientos, además de la inducción de respuestas defensivas en el cultivo, en dependencia de la masa molecular del quitosacárido, de la concentración y de la forma de aplicación (Costales-Menéndez et al., 2020; Hemantaranjan et al., 2014; Salachna et al., 2017; Vargas et al., 2014; Zeng et al., 2012). Sin embargo, en la literatura existe escasa información acerca del efecto de los quitosacáridos sobre microorganismos simbióticos.

El objetivo del presente trabajo fue evaluar la aplicación conjunta, de concentraciones de quitosano y el inoculante Azofert-S ${ }^{\circledR}$ sobre semillas de soya, en la supervivencia de Bradyrhizobium elkanii y el desarrollo vegetativo de las plantas.

\section{Materiales y métodos}

El trabajo se realizó en el Departamento de Fisiología y Bioquímica Vegetal del Instituto Nacional de Ciencias Agrícolas (INCA), Mayabeque, Cuba, ubicado en las coordenadas $22^{\circ} 58^{\prime} 00^{\prime \prime} \mathrm{N}$ y $82^{\circ} 09^{\prime} 00$ '”, a $130 \mathrm{msnm}$, en los meses de marzo a julio de 2016.

Se utilizó como material vegetal, la variedad de soya (Glycine max) INCAsoy-27 (IS-27), procedente del Banco de germoplasma de semillas del INCA (Ponce et al., 2006). Las semillas se sembraron en macetas plásticas de $1370,25 \mathrm{~cm}^{3}$ de volumen y $1,2 \mathrm{~kg}$ de capacidad de suelo; se permitieron crecer dos plantas por maceta en condiciones controladas.

Se empleó un suelo ferralítico rojo lixiviado típico, éutrico, proveniente del INCA (Hernández et al., 2015). El análisis químico de este suelo se realizó en el Laboratorio de Biofertilizantes y Nutrición de las Plantas de la propia institución, a partir de cuatro muestras colectadas entre 0 y $20 \mathrm{~cm}$ de profundidad, mediante los métodos descritos por Paneque-Pérez et al. (2010). El suelo presentó valores bajos de materia orgánica, pH ligeramente ácido $(6,8)$, contenido de medio a alto de $\mathrm{P}$ disponible y $\mathrm{K}^{+}$intercambiable, así como altos contenidos de $\mathrm{Ca}^{2+} \mathrm{y}$ $\mathrm{Mg}^{2+}$ intercambiables (Cuadro 1). Estos valores resultan adecuados para el cultivo de la soya, que requiere una fertilidad media (Ritchey et al., 2014).

Cuadro 1. Características químicas del suelo ferralítico rojo lixiviado típico, éutrico, utilizado en el cultivo de la soya (Glycine max), Mayabeque, Cuba, 2016.

Table 1. Chemical characteristics of the typical leached red ferralitic, eutric soil, used in the soybean (Glycine max) cultivation, Mayabeque, Cuba, 2016.

\begin{tabular}{cccccc}
\hline \multicolumn{5}{c}{ Características químicas del suelo } \\
\hline $\mathbf{p H}\left(\mathbf{H}_{\mathbf{2}} \mathbf{O}\right)$ & $\begin{array}{c}\mathbf{M . O} \\
\mathbf{g ~ k g}^{-1}\end{array}$ & $\begin{array}{c}\mathbf{P} \\
\mathbf{m g ~ k g}\end{array}$ & $\mathbf{K}^{+\mathbf{1}}$ & $\mathbf{C a}^{2+}$ & $\mathbf{M g}^{2+}$ \\
$\mathbf{C m o l}_{c} \mathbf{k g}^{-1}$ & \\
\hline 6,80 & 18,3 & 76,33 & 0,60 & 6,83 & 0,83 \\
\hline
\end{tabular}

El contenido de materia orgánica (M.O) se determinó según el método de Walkley \& Black (1934), el pH por el método potenciométrico, con una relación suelo-agua $(1: 2,5)$, los cationes intercambiables calcio $\left(\mathrm{Ca}^{2+}\right)$ y magnesio $\left(\mathrm{Mg}^{2+}\right)$ por complejometría, a partir de una extracción con $\mathrm{NH}_{4} \mathrm{OAc}\left(1 \mathrm{~mol} \mathrm{l}^{-1}\right)$ a $\mathrm{pH}=7$, el potasio $\left(\mathrm{K}^{+}\right)$por fotometría de llama y el fósforo asimilable $(\mathrm{P})$ se determinó por el método de Oniani et al. (1973), con ácido sulfúrico a $0,1 \mathrm{~g} \mathrm{l}^{-1}$ / The organic matter content (M.O) was determined following the Walkley \& Black method (1934), the $\mathrm{pH}$ for the potentiometric method, with a soil-water relationship $(1: 2,5)$, the exchangeable cations calcium $\left(\mathrm{Ca}^{2+}\right)$, and magnesium $\left(\mathrm{Mg}^{2+}\right)$ by complexometry, starting from an extraction with $\mathrm{NH}_{4} \mathrm{OAc}\left(1 \mathrm{~mol} \mathrm{l}^{-1}\right)$ to $\mathrm{pH}=7$, potassium $\left(\mathrm{K}^{+}\right)$by flame photometry and the assimilable phosphorus (P) was determined following the Oniani et al. (1973) method, with sulfuric acid at $0,1 \mathrm{~g}^{-1}$. 
El inoculante comercial Azofert- $S^{\circledast}$ a base de la cepa Bradyrhizobium elkanii ICA 8001 para soya, producido y comercializado por el INCA (Nápoles, 2002), se aplicó a las semillas en dosis de $200 \mathrm{ml}$ por cada $50 \mathrm{~kg}$ de semilla y con una concentración de $2 \times 10^{10}$ unidades formadoras de colonias por mililitro (UFC ml-1).

El polímero de quitosano comercial (PANVO Chemicals, India), se caracterizó mediante viscosimetría y espectrometría infrarroja por el Grupo de Productos Bioactivos del INCA, entre sus características físico-químicas tiene una masa molar de $100 \mathrm{kDa}$ y un grado de acetilación del 13,7\%. A partir de una solución madre de $10 \mathrm{~g} \mathrm{l}^{-1}$ de quitosano disuelto en ácido acético $(1 \%)$ y ajustada a $\mathrm{pH}=5,2$ con $\mathrm{KOH}$, se tomaron alícuotas para preparar las diferentes concentraciones a evaluar: 10,50,100,500,1000 y $2000 \mathrm{mg} \mathrm{l}^{-1}$ (Costales et al., 2016; Costales-Menéndez et al., 2020) equivalentes a las dosis de: $0,2,1,2,10,20$ y $40 \mu \mathrm{g}$ de quitosano por g de semilla, respectivamente, en la proporción de un litro de solución de quitosano para $50 \mathrm{~kg}$ de semilla.

\section{Ensayo de compatibilidad quitosano-Bradyrhizobium en semillas de soya}

Los vasos de precipitado con 150 semillas se inocularon con el inoculante Azofert- $\mathrm{S}^{\circledR}$ (T1) y el resto de los tratamientos correspondieron a las mezclas del inoculante y las diferentes concentraciones de quitosano: T2 (10 $\left.\mathrm{mg} \mathrm{l}^{-1}\right)$, T3 $\left(50 \mathrm{mg} \mathrm{l}^{-1}\right)$, T4 $\left(100 \mathrm{mg} \mathrm{l}^{-1}\right)$, T5 $\left(500 \mathrm{mg} \mathrm{l}^{-1}\right)$ y T6 $\left(1000 \mathrm{mg} \mathrm{l}^{-1}\right)$. Transcurrida una hora, se taparon con papel de aluminio, se almacenaron en condiciones de oscuridad a temperatura ambiente $\left(25 \pm 2{ }^{\circ} \mathrm{C}\right)$ y se evaluó la supervivencia de Bradyrhizobium a los 0, 3 y 10 días de almacenadas las semillas, de acuerdo con la norma ISO9001/14001, que emplea la empresa Rizobacter Argentina S.A.

Se colocaron diez semillas (dos réplicas por tratamiento) en tubos con solución salina estéril (10 ml, 0,85 $\%$ ), se agitaron en vórtex durante 10 min a $200 \mathrm{rpm}$ y se realizaron diluciones seriadas en tubos de ensayo con agua destilada estéril, a partir de $1 \mathrm{ml}$ de las suspensiones de semillas. Se emplearon seis placas Petri con medio manitol extracto de levadura agar (Vincent, 1970) e indicador rojo congo para la siembra por diseminación, de las diluciones $10^{-3}, 10^{-4}$ y $10^{-5}$ y se incubaron a $29,5{ }^{\circ} \mathrm{C}$ durante siete días. En función de la dilución utilizada, se contó el número de colonias por placa y se calculó el número de bacterias por semilla ( $\mathrm{UFC}^{-1} \mathrm{l}^{-1}$ ). Los datos se procesaron mediante un análisis de varianza simple con el programa estadístico Statgraphics (versión 5, 2011). Las medias con diferencias significativas se compararon a través de la prueba de mínima diferencia significativa (LSD).

\section{Quitosano-Bradyrhizobium en el desarrollo vegetativo de plantas de soya}

A las semillas de soya se les adicionó la mezcla de inóculo de Azofert-S ${ }^{\circledast}\left(1 \times 10^{9} \mathrm{UFC}^{-1}\right)$ y cada concentración de quitosano correspondiente a los tratamientos T3 $\left(10 \mathrm{mg} \mathrm{l}^{-1}\right)$, T4 (50 $\left.\mathrm{mg} \mathrm{l}^{-1}\right)$, T5 (100 $\left.\mathrm{mg} \mathrm{l}^{-1}\right)$, T6 (500 mg l-1), T7 (1000 $\mathrm{mg} \mathrm{l}^{-1}$ ) y T8 (2000 $\left.\mathrm{mg} \mathrm{l}^{-1}\right)$, además de un control absoluto (T1) sin presencia de quitosano ni de inóculo y otro solo inoculado con el microsimbionte (T2), como se describió en el experimento anterior. Las semillas se dejaron secar por una hora antes de sembrarlas en las macetas con suelo, se colocaron en un cuarto de crecimiento de plantas mediante un diseño completamente aleatorizado, con un ciclo de $16 / 8 \mathrm{~h}$ luz/oscuridad, temperatura entre 25 y $27^{\circ} \mathrm{C}$ y humedad relativa del aire entre 50 y $70 \%$.

Cuando las plantas de soya alcanzaron la etapa V4 de crecimiento, se seleccionaron treinta plantas por tratamiento, que se extrajeron de sus macetas, se lavaron sus raíces y se escurrieron sobre papel de filtro, durante 30 min antes de efectuar las evaluaciones morfoagronómicas, relacionadas con la nodulación, la fisiología y el crecimiento de las plantas. Todas las determinaciones bioquímicas se realizaron en los terceros trifoliolos desarrollados, a partir de tres muestras por tratamiento con tres repeticiones de laboratorio cada una.

Se determinó el número de nódulos en la raíz principal (RP), en las raíces secundarias (RS) y los totales (NT), mediante conteo directo y sus respectivas masas secas, así como el porcentaje de efectividad de los nódulos totales 
(\%) por planta, mediante el corte transversal de los mismos y la visualización de color rojizo por la presencia de leghemoglobina en su interior (Pommeresche \& Hansen, 2017).

La actividad enzimática de la nitrato reductasa (NR, $\mu$ mol $\mathrm{NO}_{2} \mathrm{~g}^{-1} \mathrm{~h}^{-1}$ ) se determinó en segmentos pequeños (entre 1-1,5 cm) de trifoliolos (Blondel \& Blanc, 1975), las muestras se leyeron a una absorbancia de $540 \mathrm{~nm}$ en un espectrofotómetro UV/Visible (Genesys 6, Thermo Electron Corporation). Se realizó una curva patrón de $\mathrm{NaNO}_{2}$ en concentraciones desde 2 hasta $24 \mathrm{nmol}$ y la actividad NR se expresó como el incremento de nitrito en base a la masa fresca foliar.

La concentración de macronutrientes ( $\mathrm{g} \mathrm{kg}^{-1}$ de muestra seca) se determinó en nódulos y terceros trifoliolos: el nitrógeno $(\mathrm{N})$ por el método Nessler, el fósforo $(\mathrm{P})$ por la formación de azul de molibdeno y el potasio $(\mathrm{K})$ por fotometría de llama. De cada órgano se tomaron tres muestras secas y se molieron (Moulinex Super Junior, RS 0819042, Francia), de 0,5 g por tratamiento en el caso de las hojas y dos muestras para los nódulos, por no contar con suficiente cantidad de estos. La concentración de los iones calcio (Ca), magnesio (Mg), manganeso (Mn), cobre $(\mathrm{Cu})$, cobalto $(\mathrm{Co})$ y sodio $(\mathrm{Na})\left(\mathrm{mg} \mathrm{kg}^{-1}\right)$, se determinó en los órganos de soya por espectrofotometría de absorción atómica de llama (Analytikjena, modelo Nova A 350, Alemania). Para ello, se realizó la digestión de las muestras con ácido nítrico $\left(\mathrm{HNO}_{3}, 4 \mathrm{~m}\right)$ concentrado, en horno microondas por 20 min y temperatura máxima de $190{ }^{\circ} \mathrm{C}$. De acuerdo con la norma ISO-11466, se realizaron curvas patrones y diluciones con agua desionizada para cada elemento, excepto para Ca y $\mathrm{Mg}$ que se diluyeron en una solución de cloruro de lantano $(0,2 \%)$. No se encontró presencia de $\mathrm{Na}$ en ninguna de las muestras estudiadas.

El contenido relativo de clorofilas totales (unidades Spad) se determinó en el haz de los terceros trifoliolos (de arriba hacia abajo), de color uniforme y fuera de la nervadura central con un medidor portátil (MINOLTA SPAD* 502 plus).

Se prepararon $3 \mathrm{ml}$ de extractos etanólicos $(80 \%)$ de trifoliolos $(0,25 \mathrm{~g}$ de polvo seco) de cada tratamiento, que se agitaron en vórtex durante $30 \mathrm{~s}$ y se colocaron en baño María $\left(85^{\circ} \mathrm{C}\right)$, durante $30 \mathrm{~min}$. Luego, se centrifugaron a $11823 \mathrm{~g}, 5{ }^{\circ} \mathrm{C}$ por $15 \mathrm{~min}$, repitiéndose el procedimiento dos veces más. Cada sobrenadante recolectado (aproximado $9 \mathrm{ml}$ ) se evaporó hasta $3 \mathrm{ml}$ en baño de arena y se completó hasta $10 \mathrm{ml}$ con agua destilada. A los extractos foliares se les determinó la concentración de carbohidratos solubles totales y reductores (mg de glucosa $\mathrm{g}^{-1}$ ) por el método de Antrona y de Nelson (Somogyi, 1952), respectivamente. Los valores obtenidos de nueve repeticiones por tratamiento se interpolaron en una curva de calibración realizada con patrón de glucosa (SIGMA) para ambos metabolitos, a concentraciones desde 0,004 hasta $0,04 \mathrm{mg}(\lambda=630 \mathrm{~nm})$ para los carbohidratos totales (Yemm \& Willis, 1954) y concentraciones desde 0,008 hasta $0,125 \mathrm{mg}(\lambda=520 \mathrm{~nm})$ para los carbohidratos reductores. Las concentraciones de flavonoides (Gajula et al., 2009) y de fenoles totales (Singlenton \& Rossi, 1965) (mg equivalente en $100 \mathrm{~g}$ ) se determinaron mediante curvas patrones de quercetina (de 0,1 a 0,6 mg QC) y de ácido gálico (de 0,003 a 0,0255 mg AG), respectivamente, también en muestras secas colectadas de terceros trifoliolos.

Se evaluaron variables morfoagronómicas relacionadas con el crecimiento de las plantas de soya: el diámetro $(\mathrm{mm})$ y la longitud del tallo $(\mathrm{cm})$, con un pie de rey (vernier o calibre) electrónico digital $(0-150 \mathrm{~mm}$, China) y una regla graduada (1 mm de precisión), desde la base del tallo hasta el brote de la hoja terminal, respectivamente. Se midió con la regla graduada (1 $\mathrm{mm}$ de precisión) la longitud radical $(\mathrm{cm})$ desde la base del cuello hasta la cofia de la raíz principal. La masa seca $\left(\mathrm{g}_{\mathrm{p}} \mathrm{planta}^{-1}\right)$ de los órganos de soya se determinó en una balanza analítica Sartorius CPA 3245, luego de colocar las muestras en una estufa de aire forzado (BINDER, USA) durante $72 \mathrm{~h}$, a $75^{\circ} \mathrm{C}$ hasta obtener peso constante. El área foliar $\left(\mathrm{cm}^{2}\right)$ se determinó en todas las hojas trifoliadas por método destructivo de la planta con un medidor portátil (AM 300, UK).

A los datos obtenidos se les verificó los supuestos de normalidad y homogeneidad de varianza por las pruebas de Kolmogorov - Smirnov \& Levene, además de realizarles un ANOVA de clasificación simple, mediante el paquete estadístico Statgraphics. La comparación de las medias resultantes se realizó por la Prueba de Tukey HSD p< 0,05 y los gráficos se realizaron en SigmaPlot (versión 11, 2008). 


\section{Resultados}

La supervivencia de Bradyrhizobium elkanii en las semillas de soya para todos los tratamientos, disminuyó con el tiempo de almacenamiento y, aunque hubo diferencias significativas entre tratamientos, a los cero y diez días, todos se mantuvieron en el mismo orden exponencial de concentración celular para cada momento evaluado. El recuento de células viables, mostró que las diferentes concentraciones del polímero aplicadas no tuvieron efecto inhibitorio en la bacteria durante el tiempo de almacenaje, comparado con la sola inoculación del inoculante Azofert- $S^{\circledast}$ (T1) (Figura 1).

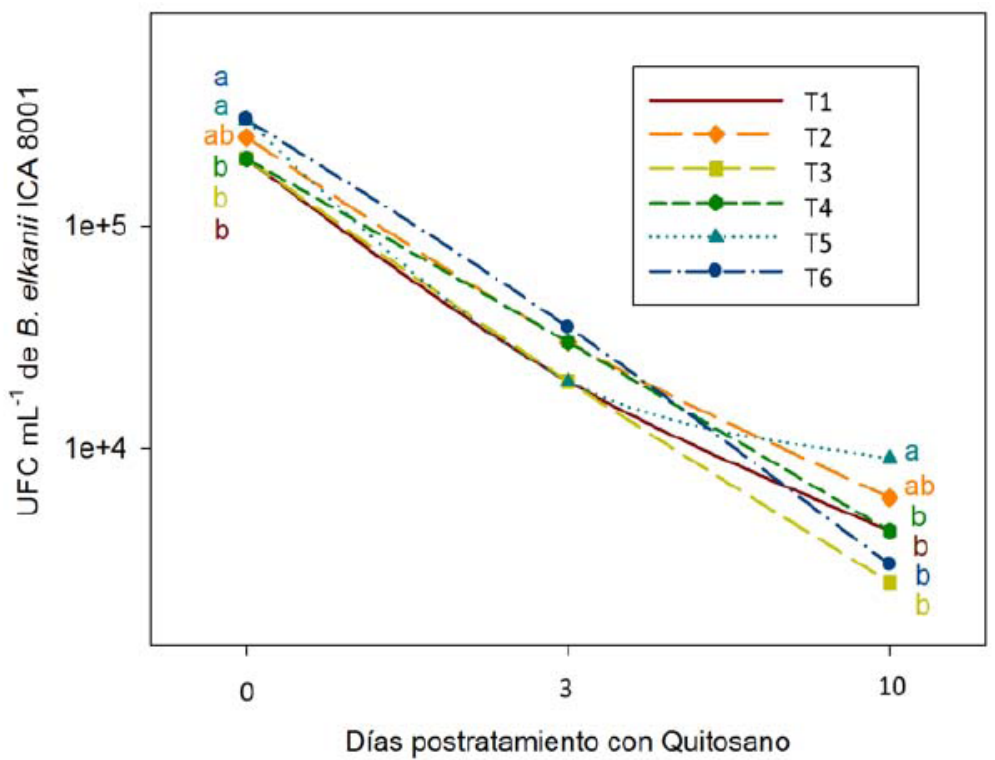

Figura 1. Número de Bradyrhizobium viables en semillas de soya (Glycine max) INCAsoy-27 (IS-27), inoculadas y tratadas con diferentes concentraciones de quitosano. Mayabeque, Cuba, 2016.

Medias con letras iguales no difieren estadísticamente para $\mathrm{p}<0,05$, según la Prueba LSD. Error estándar del experimento $(n=6)$, ES $\overline{\mathrm{X}}(0$ días $)=2,0412 \times 10^{4}, \operatorname{ES} \overline{\mathrm{X}}(3$ días $)=8,4162 \times 10^{3}$ y ES $\overline{\mathrm{X}}(10$ días $)=0,62915 \times 10^{2}$.

T1: Azofert-S ${ }^{\circledR}, \mathrm{T} 2: 10 \mathrm{mg} \mathrm{l}^{-1}$, T3: $50 \mathrm{mg} \mathrm{l}^{-1}$, T4: $100 \mathrm{mg} \mathrm{l}^{-1}$, T5: $500 \mathrm{mg} \mathrm{l}^{-1} \mathrm{y} \mathrm{T}^{\mathrm{T}}: 1000 \mathrm{mg} \mathrm{l}^{-1}$.

Figure 1. Number of viable Bradyrhizobium on inoculated soybean (Glycine max) seed INCAsoy-27 (IS-27) seeds, inoculated and treated with different chitosan concentrations. Mayabeque, Cuba, 2016.

Means with same letters do not differ statistically for $\mathrm{p}<0.05$, according to the Test LSD. Standard error of the experiment $(n=6)$, ES $\overline{\mathrm{X}}(0$ days $)=2,0412 \times 10^{4}$, ES $\overline{\mathrm{X}}(3$ days $)=8,4162 \times 10^{3}$ y ES $\overline{\mathrm{X}}(10$ days $)=0,62915 \times 10^{2}$.

T1: Azofert-S ${ }^{\circledast}, \mathrm{T} 2: 10 \mathrm{mg} \mathrm{l}^{-1}$, T3: $50 \mathrm{mg} \mathrm{l}^{-1}$, T4: $100 \mathrm{mg} \mathrm{l}^{-1}$, T5: $500 \mathrm{mg} \mathrm{l}^{-1} \mathrm{y} \mathrm{T}^{\mathrm{T}}: 1000 \mathrm{mg} \mathrm{l}^{-1}$.

El quitosano a concentraciones de 500 y $1000 \mathrm{mg} \mathrm{l}^{-1}$ (T5 y T6) tuvo los mayores valores de células viables sobre semillas, por encima del resto de los tratamientos, en el primer momento (0 días). A los tres días de almacenaje no hubo diferencias significativas entre los tratamientos. Sin embargo, a los diez días de almacenadas las semillas, solo la concentración $500 \mathrm{mg} \mathrm{l}^{-1}$ (T5) mostró un efecto positivo en el número de UFC $\mathrm{ml}^{-1}$ comparada con el tratamiento control (T1) (Figura 1). 
La aplicación conjunta del Azofert ${ }^{\circledR}-\mathrm{S}$ y quitosano en semillas previo a la siembra, no mejoró la respuesta en el número de nódulos formados (RP, RS y NT) en las plantas, respecto al tratamiento inoculado (T2), excepto el tratamiento T6 (500 $\mathrm{mg} \mathrm{L}^{-1}$ ) que aumentó la masa seca de los nódulos formados en las raíces principales (Figura 2A) y el tratamiento T4 (50 $\left.\mathrm{mg} \mathrm{L}^{-1}\right)$ que provocó una menor masa en los nódulos de las raíces secundarias (Figura 2B). Todos los nódulos formados fueron cien por ciento efectivos, lo que se pudo constatar por la presencia de la leghemoglobina, al visualizarse el color rojizo en el interior de los mismos.

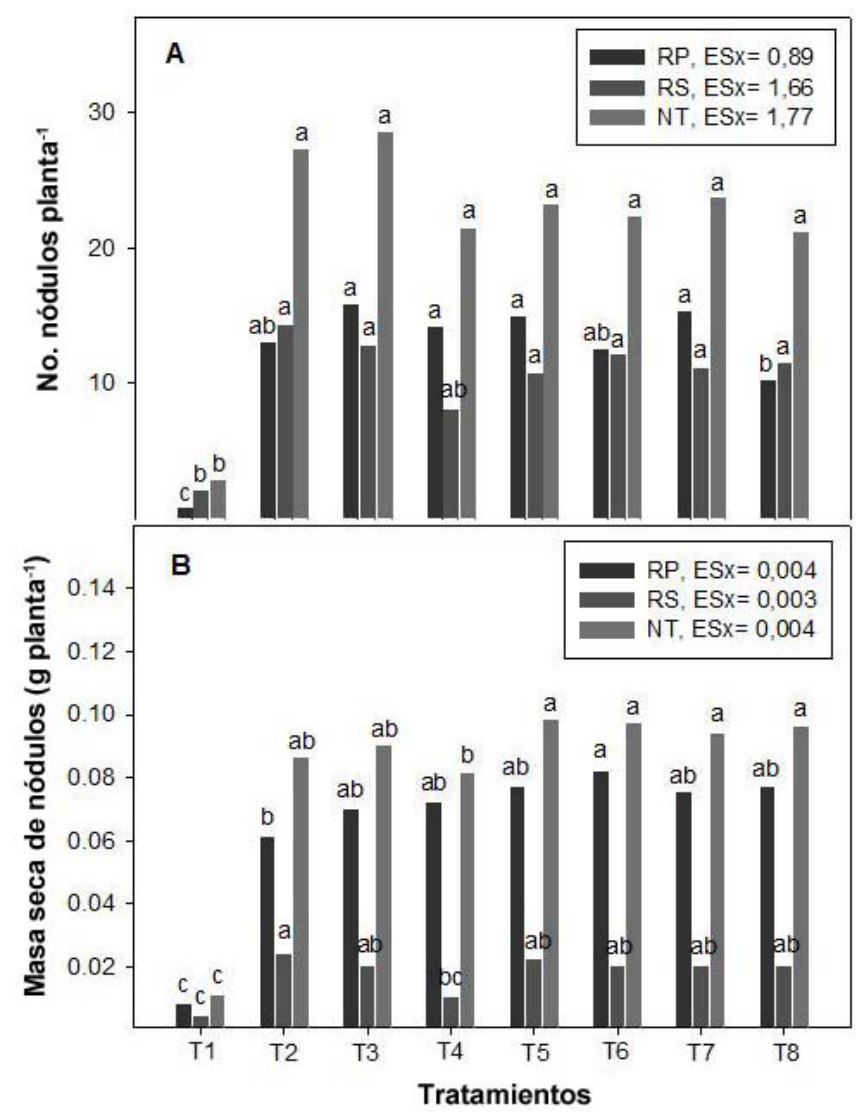

Figura 2. Efecto de la adición conjunta del inoculante Azofert- $\mathrm{S}^{\circledR}$ y el quitosano a las semillas de soya (Glycine max) INCAsoy-27 (IS-27), en el número (A) y la masa seca (B) de los nódulos totales (NT), los de la raíz principal (RP) y los de raíces secundarias (RS) de plantas cultivadas en cuarto de crecimiento. Mayabeque, Cuba, 2016.

Medias con letras iguales no difieren estadísticamente para p<0,05, según la Prueba de Rangos Múltiples de Tukey HSD. ES X̄: Error estándar del experimento $(n=30)$.

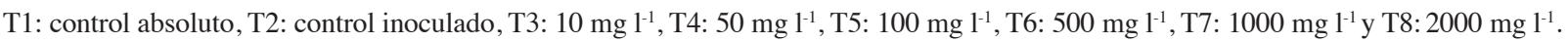

Figure 2. Effect of the joint addition of the Azofert ${ }^{\circledR}$ inoculant and chitosan to soybean (Glycine max) INCAsoy-27 (IS-27) seeds, in the number (A) and the dry mass (B) of the total nodules (NT), those of the main root (RP) and those of secondary roots (RS) of plants cultivated in a growth room. Mayabeque, Cuba, 2016.

Means with same letters don't differ statistically for $\mathrm{p}<0.05$, according to the Test of Multiple Ranges of Tukey HSD. ES $\overline{\mathrm{x}}$ : Standard error of the experiment $(n=30)$.

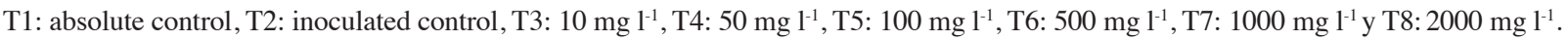


La actividad de la nitrato reductasa (NR) determinada en hojas de soya (Glycine max), resultó superior con la aplicación de Azofert ${ }^{\circledR}$ y quitosano a $500 \mathrm{mg} \mathrm{l}^{-1}$ (T6), con 69 y $49 \%$ de incremento, respecto al T1 y al T2, respectivamente. El resto de los tratamientos no mostraron diferencias significativas entre ellos (Figura 3).

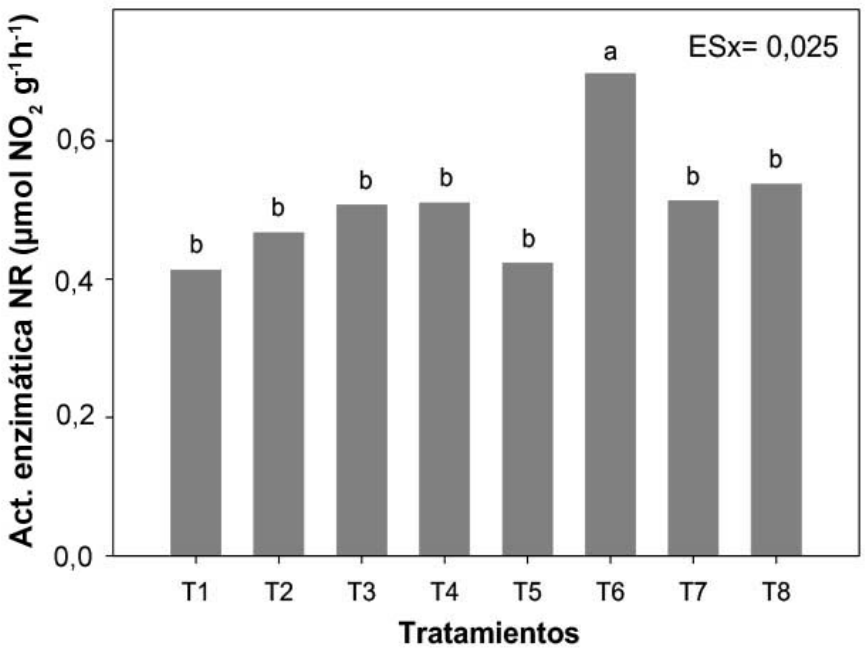

Figura 3. Efecto de la adición conjunta del inoculante Azofert-S ${ }^{\circledR}$ y el quitosano a las semillas de soya (Glycine max) INCAsoy-27 (IS-27), en la actividad de la nitrato reductasa (NR) en hojas de soya cultivada en cuarto de crecimiento. Mayabeque, Cuba, 2016.

Medias con letras iguales no difieren estadísticamente para p<0,05, según la Prueba de Rangos Múltiples de Tukey HSD. ES X̄: Error estándar del experimento $(n=9)$.

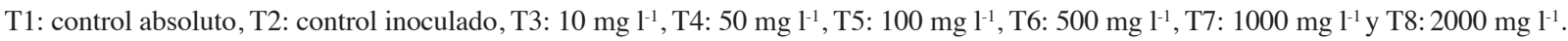

Figure 3. Effect of the combined addition of the Azofert-S® inoculant and chitosan to soybean (Glycine max) INCAsoy-27 (IS-27) seeds, on the nitrate reductase (NR) activity in leaves of soybean cultivated in a growth room. Mayabeque, Cuba, 2016.

Means with same letters don't differ statistically for $\mathrm{p}<0.05$, according to the Test of Multiple Ranges of Tukey HSD. ES $\bar{x}$ : Standard error of the experiment $(n=9)$.

T1: absolute control, T2: inoculated control, T3: $10 \mathrm{mg} \mathrm{l}^{-1}$, T4: $50 \mathrm{mg} \mathrm{l}^{-1}$, T5: $100 \mathrm{mg} \mathrm{l}^{-1}$, T6: $500 \mathrm{mg} \mathrm{l}^{-1}$, T7: $1000 \mathrm{mg} \mathrm{l}^{-1} \mathrm{y} \mathrm{T}^{\mathrm{T}}: 2000 \mathrm{mg} \mathrm{l}^{-1}$.

La aplicación de quitosano no mejoró la respuesta encontrada en la concentración de $\mathrm{N}$ en las plantas inoculadas (T2), tratamiento que logró incrementar este elemento en nódulos en un $29 \%$ y en hojas en un $53 \%$, respecto a T1 (Cuadros 2 y 3). La concentración de P en nódulos y hojas no mostró diferencias significativas entre los tratamientos, sin embargo, la concentración de $\mathrm{K}$ en nódulos disminuyó con los tratamientos T2, T5 (100 mg l-1) y T6 (500 mg 1-1). Los mayores valores de este macroelemento en nódulos se encontraron con el tratamiento T2, además de T7 (1000 $\mathrm{mg}^{-1}$ ) y T8 (2000 $\left.\mathrm{mg} \mathrm{l}^{-1}\right)$, con incrementos desde 30,12 \% hasta el $41 \%$, con relación a T2 (Cuadro 3).

Todos los tratamientos de quitosano presentaron mayor contenido de Ca en los nódulos (con aumentos entre 1 y $6 \%$ ), respecto al control inoculado (T2). La concentración de Ca fue proporcional al aumento de la concentración

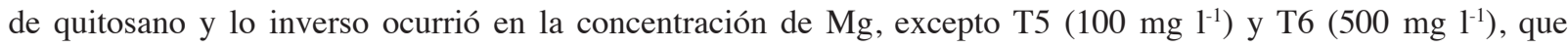
alcanzaron los mayores y los menores valores, respectivamente. La presencia de oligoelementos en los nódulos se favoreció con la inoculación de las plantas (T2) y con el tratamiento T8 (2000 $\mathrm{mg} \mathrm{l}^{-1}$ de quitosano) (Cuadro 3). De igual modo, T8 también incrementó las concentraciones de $\mathrm{K}, \mathrm{Ca}, \mathrm{Mg}, \mathrm{Mn}, \mathrm{Cu}$ y Co en hojas, en 25, 117, 9, 38, 31 y $59 \%$, respectivamente, con relación a T2, aunque en algunos casos no se diferenció de T7 (1000 mg 1-1 de quitosano) (Cuadro 2). 
Cuadro 2. Efecto de la adición conjunta del inoculante Azofert- $\mathrm{S}^{\circledR}$ y el quitosano a las semillas de soya (Glycine max) INCAsoy-27 (IS27), en la concentración de nutrientes en hojas trifoliadas de soya, cultivada en cuarto de crecimiento de plantas. Mayabeque, Cuba, 2016.

Table 2. Effect of the joint addition of the Azofert-S® inoculant and chitosan on soybean (Glycine max) INCAsoy-27 (IS-27) seeds, in the nutrient concentration in trifoliate leaves of soybean, cultivated in plant growth room. Mayabeque, Cuba, 2016.

\begin{tabular}{|c|c|c|c|c|c|c|c|c|}
\hline \multirow[t]{3}{*}{ Tratamientos } & \multicolumn{8}{|c|}{ Concentración de nutrientes en hojas } \\
\hline & $\mathbf{N}$ & $\mathbf{P}$ & $\mathbf{K}$ & Ca & Mg & Mn & $\mathbf{C u}$ & Co \\
\hline & \multicolumn{4}{|c|}{$\mathrm{g} \mathrm{kg}^{-1}$} & \multicolumn{4}{|c|}{$\mathrm{mg} \mathrm{kg}^{-1}$} \\
\hline T1 & $20,9 \mathrm{~b}$ & 5,3 & $21,4 \mathrm{c}$ & $5,0 \mathrm{~g}$ & $3,5 \mathrm{~d}$ & $15,0 \mathrm{~d}$ & $5,30 \mathrm{e}$ & $0,07 \mathrm{c}$ \\
\hline $\mathbf{T} 2$ & $32,1 \mathrm{a}$ & 3,4 & $22,2 \mathrm{bc}$ & $8,3 \mathrm{f}$ & $4,3 \mathrm{bc}$ & $21,0 \mathrm{c}$ & $6,50 \mathrm{~cd}$ & $0,17 \mathrm{~b}$ \\
\hline $\mathbf{T 3}$ & $31,1 \mathrm{a}$ & 3,0 & $20,7 \mathrm{~cd}$ & $10,1 \mathrm{e}$ & $4,1 \mathrm{c}$ & $21,0 \mathrm{c}$ & $6,83 \mathrm{c}$ & $0,16 \mathrm{~b}$ \\
\hline T4 & 32,9 a & 2,8 & $20,0 \mathrm{~cd}$ & $12,1 \mathrm{~d}$ & $3,5 \mathrm{~d}$ & $21,0 \mathrm{c}$ & $5,85 \mathrm{de}$ & $0,14 \mathrm{~b}$ \\
\hline T5 & $36,4 \mathrm{a}$ & 3,4 & $18,0 \mathrm{~d}$ & $13,9 \mathrm{~cd}$ & $3,6 \mathrm{~d}$ & $24,0 \mathrm{~b}$ & $5,60 \mathrm{e}$ & $0,14 \mathrm{~b}$ \\
\hline T6 & $35,5 \mathrm{a}$ & 3,2 & $19,7 \mathrm{~cd}$ & $15,3 \mathrm{bc}$ & $3,7 \mathrm{~d}$ & $24,0 \mathrm{~b}$ & $5,92 \mathrm{de}$ & $0,14 \mathrm{~b}$ \\
\hline T7 & $35,3 \mathrm{a}$ & 3,2 & $25,4 \mathrm{ab}$ & $16,9 \mathrm{ab}$ & $4,5 \mathrm{ab}$ & $28,0 \mathrm{a}$ & $7,65 \mathrm{~b}$ & $0,23 \mathrm{a}$ \\
\hline T8 & 36,8 a & 3,6 & $27,8 \mathrm{a}$ & $18,0 \mathrm{a}$ & $4,7 \mathrm{a}$ & $29,0 \mathrm{a}$ & $8,54 \mathrm{a}$ & $0,27 \mathrm{a}$ \\
\hline ES $\bar{x}$ & 1,2 & $0,3(\mathrm{~ns})$ & 1,3 & 0,36 & 0,6 & 0,04 & 0,01 & 0,01 \\
\hline
\end{tabular}

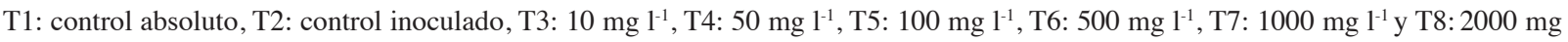
$1^{-1}$. Medias con letras iguales no difieren estadísticamente para $\mathrm{p}<0,05$, según la Prueba de Rangos Múltiples de Tukey HSD. ES $\bar{x}$ : error estándar del experimento $(n=6)$ / T1: absolute control, T2: inoculated control, T3: $10 \mathrm{mg} \mathrm{l}^{-1}$, T4: $50 \mathrm{mg} \mathrm{l^{-1 }}$, T5: $100 \mathrm{mg} \mathrm{l}{ }^{-1}$, T6: $500 \mathrm{mg}$ $1^{-1}$, T7: $1000 \mathrm{mg} \mathrm{l}^{-1} \mathrm{y} \mathrm{T}: 2000 \mathrm{mg} \mathrm{l}^{-1}$. Means with same letters do not differ statistically for $\mathrm{p}<0,05$, according to the Test of Multiple Ranges of Tukey HSD. ES: standard error of the experiment $(n=3)$.

Cuadro 3. Efecto de la adición conjunta del inoculante Azofert- $S^{\circledR}$ y de quitosano en la concentración de nutrientes en nódulos formados en soya (Glycine max) INCAsoy-27 (IS-27), cultivada en un cuarto de crecimiento de plantas. Mayabeque, Cuba, 2016.

Table 3. Effect of the joint addition of the Azofert-S® inoculant and chitosan in the nutrient concentration of nodules formed in soybean (Glycine max) INCAsoy-27 (IS-27) seeds cultivated in a plant growth room. Mayabeque, Cuba, 2016.

\begin{tabular}{|c|c|c|c|c|c|c|c|c|}
\hline \multirow[t]{3}{*}{ Tratamientos } & \multicolumn{8}{|c|}{ Concentración de nutrientes en nódulos } \\
\hline & $\mathbf{N}$ & $\mathbf{P}$ & $\mathbf{K}$ & $\mathbf{C a}$ & Mg & Mn & $\mathrm{Cu}$ & Co \\
\hline & \multicolumn{4}{|c|}{$\mathrm{g} \mathrm{kg}^{-1}$} & \multicolumn{4}{|c|}{$\mathrm{mg} \mathrm{kg}^{-1}$} \\
\hline $\mathbf{T 1}$ & $40,4 \mathrm{~b}$ & 4,3 & $10,8 \mathrm{a}$ & $\mathrm{Nd}$ & $\mathrm{Nd}$ & $\mathrm{Nd}$ & $\mathrm{Nd}$ & $\mathrm{Nd}$ \\
\hline $\mathbf{T 2}$ & 50,6 a & 4,8 & $8,3 \mathrm{bc}$ & $14,9 \mathrm{~d}$ & $1,9 \mathrm{~b}$ & $12,0 \mathrm{a}$ & $11,0 \mathrm{a}$ & $0,20 \mathrm{ab}$ \\
\hline T3 & $45,0 \mathrm{ab}$ & 4,1 & $10,0 \mathrm{ab}$ & $15,1 \mathrm{c}$ & $1,9 \mathrm{~b}$ & $12,0 \mathrm{a}$ & $9,9 \mathrm{~b}$ & $0,19 a b$ \\
\hline T4 & $49,7 \mathrm{ab}$ & 4,9 & $10,3 \mathrm{ab}$ & $15,2 \mathrm{c}$ & $1,9 \mathrm{~b}$ & $11,0 \mathrm{~b}$ & $10,0 \mathrm{ab}$ & $0,18 \mathrm{~b}$ \\
\hline T5 & $49,4 a b$ & 4,4 & $6,7 \mathrm{c}$ & $15,4 \mathrm{~b}$ & $2,0 \mathrm{a}$ & $11,0 \mathrm{~b}$ & $9,7 \mathrm{~b}$ & $0,18 \mathrm{~b}$ \\
\hline T6 & $48,0 \mathrm{ab}$ & 4,6 & $6,4 \mathrm{c}$ & $15,5 \mathrm{~b}$ & $1,4 \mathrm{~d}$ & $11,0 \mathrm{~b}$ & $9,4 \mathrm{~b}$ & $0,18 \mathrm{~b}$ \\
\hline T7 & $48,0 \mathrm{ab}$ & 4,9 & $11,7 \mathrm{a}$ & $15,8 \mathrm{a}$ & $1,7 \mathrm{c}$ & $11,0 \mathrm{~b}$ & $10,0 a b$ & $0,19 \mathrm{ab}$ \\
\hline T8 & $52,0 \mathrm{a}$ & 4,3 & $10,8 \mathrm{a}$ & $15,8 \mathrm{a}$ & $1,7 \mathrm{c}$ & $12,0 \mathrm{a}$ & $11,0 \mathrm{a}$ & $0,22 \mathrm{a}$ \\
\hline ES $\bar{x}$ & 1,7 & 0,3 (ns) & 0,3 & 0,02 & 0,01 & 0,10 & 0,01 & 0,006 \\
\hline
\end{tabular}

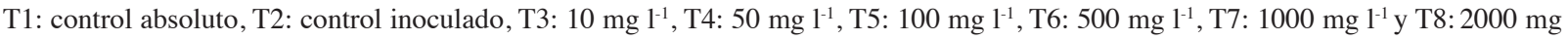
$1^{-1}$. Nd: la concentración de $\mathrm{Ca}, \mathrm{Mg}, \mathrm{Mn}, \mathrm{Cu}$ y Co no se determinó en las plantas controles (T1) por no haber suficientes nódulos para el análisis. Medias con letras iguales no difieren estadísticamente para $\mathrm{p}<0,05$, según la Prueba de Rangos Múltiples de Tukey HSD.

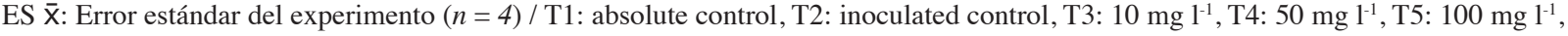
T6: $500 \mathrm{mg} \mathrm{l}^{-1}$, T7: $1000 \mathrm{mg} \mathrm{l}^{-1}$ y T8: $2000 \mathrm{mg} \mathrm{l}^{-1}$. $N d$ : the concentration of $\mathrm{Ca}, \mathrm{Mg}, \mathrm{Mn}, \mathrm{Cu}$, and Co was not determined in the control plants (CA) for not having enough nodules for the analysis. Means with same letters don't differ statistically for $\mathrm{p}<0.05$, according to the Test of Multiple Ranges of Tukey HSD. ES X̃ : Standard error of the experiment $(n=2)$. 
La concentración de N y P fue mayor en nódulos que en hojas, sin embargo, ocurrió lo inverso con la concentración de $\mathrm{K}$ y $\mathrm{Mg}$. El rango de valores del resto de los nutrientes fue similar en ambos órganos. La concentración de los diferentes nutrientes en nódulos varió en dependencia de la concentración de quitosano. Sin embargo, hubo un efecto positivo en hojas con la aplicación de las concentraciones intermedias a altas de quitosano, adicionado al inóculo de Bradyrhizobium. Los mejores resultados en los contenidos de nutrientes en ambos órganos de las plantas de soya se encontraron con los tratamientos T7 (1000 $\left.\mathrm{mg} \mathrm{l}^{-1}\right)$ y T8 (2000 $\left.\mathrm{mg} \mathrm{l}^{-1}\right)$ de quitosano (Cuadros 2 y 3).

Otra variable fisiológica determinada en hojas de soya fue el contenido relativo de clorofilas totales, que mostró el mayor valor (28,5 unidades Spad) con los tratamientos T6 $\left(500 \mathrm{mg} \mathrm{l}^{-1}\right)$ y T7 $\left(1000 \mathrm{mg} \mathrm{l}^{-1}\right)$ de quitosano, aunque solo se diferenciaron de T1 (control absoluto), el cual tuvo el menor valor (20,0 unidades Spad). El resto de los tratamientos de quitosano combinados con el inoculante estuvieron en el rango de 26,4 a 27,8 Spad y T2 (control inoculado) tuvo 26,0 unidades Spad por planta (datos no mostrados).

El contenido de los carbohidratos solubles totales y reductores en hojas mostró una tendencia decreciente con el tratamiento a las semillas, en concentraciones crecientes del polímero (Figura 4 A y B).

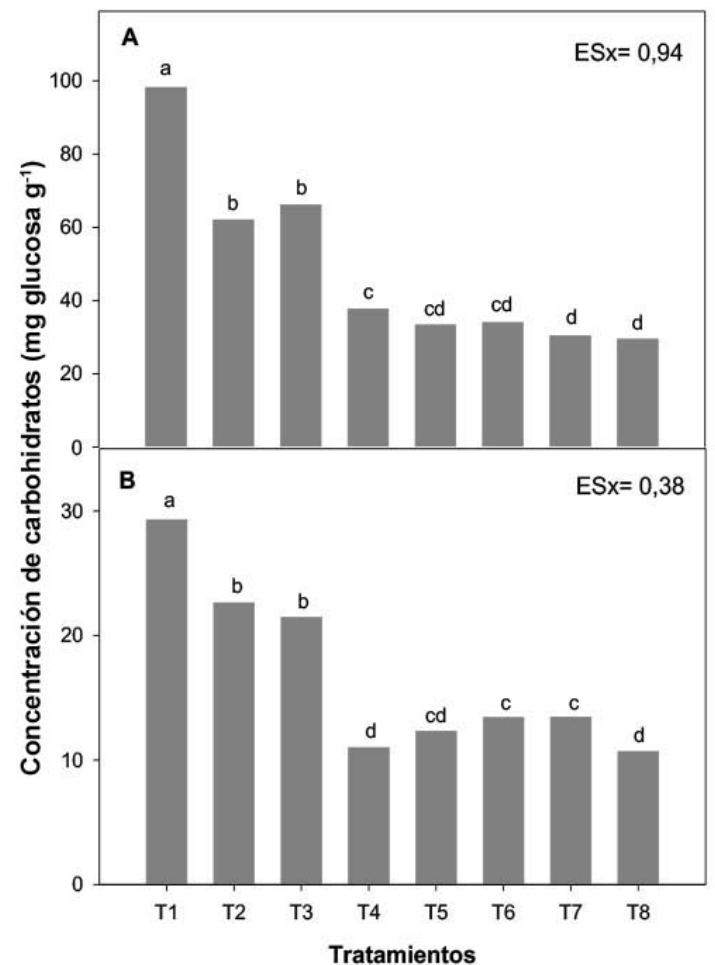

Figura 4. Efecto de la adición conjunta del inoculante Azofert-S ${ }^{\circledR}$ y el quitosano a las semillas de soya (Glycine max) INCAsoy-27 (IS-27), en la concentración de carbohidratos solubles totales (A) y reductores (B) de soya cultivada en un cuarto de crecimiento de plantas. Mayabeque, Cuba. 2016.

Medias con letras iguales no difieren estadísticamente para $\mathrm{p}<0,05$, según la Prueba de Rangos Múltiples de Tukey HSD. ES X̄: Error estándar del experimento $(n=9)$.

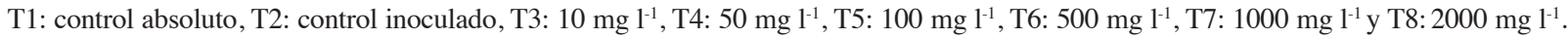

Figure 4. Effect of the combined addition of the Azofert-S® inoculant and chitosan to soybean (Glycine max) INCAsoy-27 (IS-27) seeds, in the total soluble (A) and reducing (B) carbohydrates concentration of soybean cultivated in a plant growth room. Mayabeque, Cuba. 2016.

Means with same letters do not differ statistically for $\mathrm{p}<0.05$, according to the Test of Multiple Ranges of Tukey HSD. ES $\bar{x}$ : standard error of the experiment $(n=9)$.

T1: absolute control, T2: inoculated control, T3: $10 \mathrm{mg} \mathrm{l}^{-1}$, T4: $50 \mathrm{mg} \mathrm{l}^{-1}$, T5: $100 \mathrm{mg} \mathrm{l}^{-1}$, T6: $500 \mathrm{mg} \mathrm{l}^{-1}$, T7: $1000 \mathrm{mg} \mathrm{l}^{-1} \mathrm{y} \mathrm{T8:} 2000 \mathrm{mg} \mathrm{l}^{-1}$. 
La inoculación de las plantas redujo la concentración de carbohidratos totales y reductores en más del 40 y 20 $\%$, respectivamente, comparado con el control absoluto (T1). Ambos metabolitos se redujeron significativamente más con el quitosano, excepto con la concentración menor (T3) (Figura 4 A y B). Sin embargo, tanto la inoculación (T2) como su combinación con las diferentes concentraciones de quitosano, excepto T8 (2000 $\mathrm{mg} \mathrm{l}^{-1}$ ), aumentaron significativamente los niveles de flavonoides y fenoles totales con respecto a T1 (Figura 5 A y B).

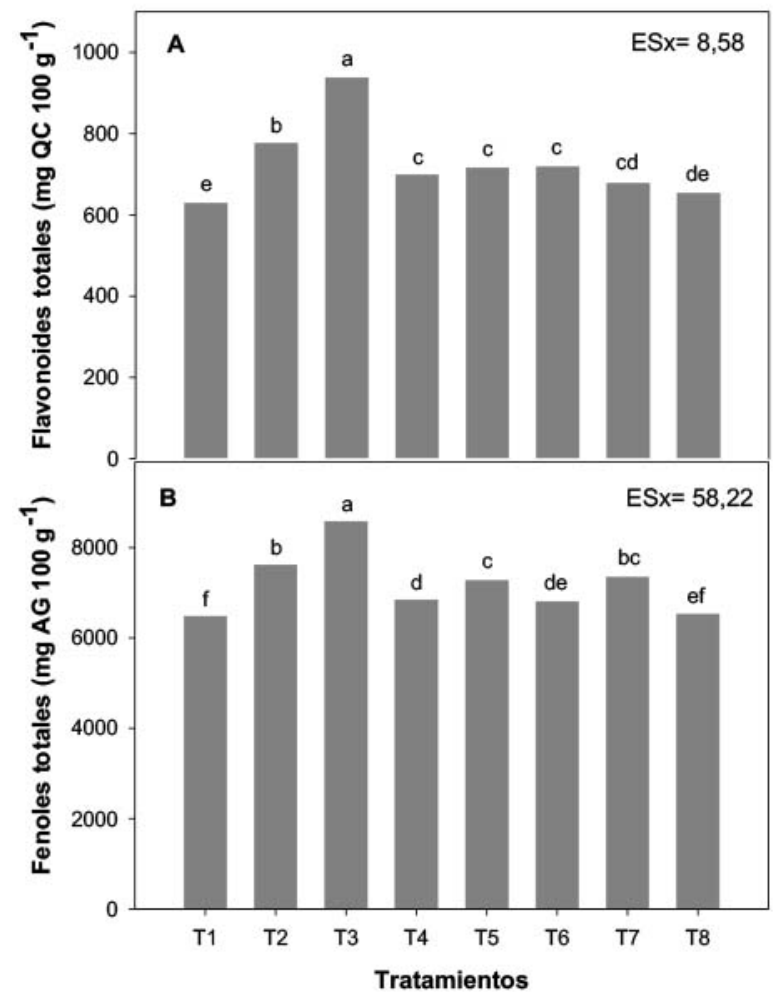

Figura 5. Efecto de la adición conjunta del inoculante Azofert-S ${ }^{\circledR}$ y el quitosano a las semillas de soya (Glycine max) INCAsoy-27 (IS27), en la concentración de flavonoides (A) y fenoles (B) totales de soya cultivada en un cuarto de crecimiento de plantas. Mayabeque, Cuba. 2016.

Medias con letras iguales no difieren estadísticamente para p<0,05, según la Prueba de Rangos Múltiples de Tukey HSD. ES X̄: Error estándar del experimento $(n=9)$.

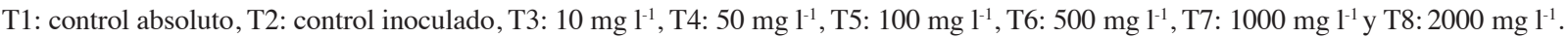

Figure 5. Effect of the combined addition of the Azofert-S® inoculant and chitosan to soybean (Glycine max) INCAsoy-27 (IS-27) seeds, in the concentration of total flavonoids (A) and phenols (B) of soybean cultivated in a plant growth room. Mayabeque, Cuba. 2016.

Means with same letters do not differ statistically for $\mathrm{p}<0.05$, according to the Test of Multiple Ranges of Tukey HSD. ES $\bar{x}$ : Standard error of the experiment $(n=9)$.

T1: absolute control, T2: inoculated control, T3: $10 \mathrm{mg} \mathrm{l}^{-1}$, T4: $50 \mathrm{mg} \mathrm{l}^{-1}$, T5: $100 \mathrm{mg} \mathrm{l}^{-1}$, T6: $500 \mathrm{mg} \mathrm{l}^{-1}$, T7: $1000 \mathrm{mg} \mathrm{l}^{-1} \mathrm{y} \mathrm{T}^{\mathrm{T}}: 2000 \mathrm{mg} \mathrm{l}^{-1}$.

El tratamiento inoculado (T2) aumentó en 23,45 y 17,45 \% los contenidos de flavonoides y fenoles, respectivamente, con respecto al control absoluto (T1), mientras que la combinación del inoculante con la concentración de $10 \mathrm{mg} \mathrm{l}^{-1}$ del polímero (T3), aumentó el contenido de flavonoides en 49 y $21 \%$ y el de los fenoles 
en 32 y $13 \%$, respecto a $\mathrm{T} 1$ y T2, respectivamente. Los tratamientos del polímero a partir de $\mathrm{T} 4\left(50 \mathrm{mg} \mathrm{l}^{-1}\right)$ para los flavonoides y entre T4 y T6 (500 $\left.\mathrm{mg} \mathrm{l}^{-1}\right)$ para los fenoles, redujeron los contenidos de ambos metabolitos respecto a T2 (Figura 5 A y B).

Varios indicadores del crecimiento vegetativo de la soya mostraron el efecto beneficioso de la combinación del inoculante Azofert- $S^{\circledR}$ y el quitosano, con respecto a las plantas que no se trataron con los bioestimulantes. Este efecto se observó en el número de hojas trifoliadas y la masa seca de la parte aérea, mientras que en el resto de las variables el efecto dependió de la concentración de quitosano. En la masa seca radical no se encontraron diferencias significativas entre los tratamientos. Los tratamientos T6 (500 $\left.\mathrm{mg} \mathrm{l}^{\mathrm{l}^{-1}}\right)$ y T7 $\left(1000 \mathrm{mg} \mathrm{l}^{-1}\right)$ estimularon el diámetro del tallo de las plantas, con incrementos de alrededor del $10 \%$, respecto a los controles (T1 y T2) (Cuadro 4).

Cuadro 4. Efecto de la adición conjunta del inoculante Azofert-S ${ }^{\circledR}$ y el quitosano (Q) a las semillas de soya (Glycine max) INCAsoy-27 (IS-27), en la respuesta morfoagronómica de soya, cultivada en un cuarto de crecimiento de plantas. Mayabeque, Cuba, 2016.

Table 4. Effect of the joint addition of the Azofert-S® inoculant and chitosan (Q) to soybean (Glycine max) INCAsoy-27 (IS-27) seeds, in the soybean morpho-agronomic response, cultivated in a plant growth room. Mayabeque, Cuba, 2016.

\begin{tabular}{|c|c|c|c|c|c|c|c|}
\hline Tratamientos & No. hojas & D. tallo $(\mathrm{mm})$ & L. tallo $(\mathrm{cm})$ & $\begin{array}{l}\text { L. radical } \\
(\mathrm{cm})\end{array}$ & MS PA (g) & $\begin{array}{c}\text { MS radical } \\
(\mathrm{g})\end{array}$ & $\begin{array}{l}\text { Área foliar } \\
\left(\mathbf{c m}^{2}\right)\end{array}$ \\
\hline T1 & $3,30 \mathrm{~b}$ & $2,35 \mathrm{~b}$ & $29,2 \mathrm{c}$ & $32,5 \mathrm{~b}$ & $0,76 \mathrm{~b}$ & 0,30 & $97,3 \mathrm{~d}$ \\
\hline $\mathbf{T} 2$ & $4,43 \mathrm{a}$ & $2,38 \mathrm{~b}$ & $32,6 \mathrm{c}$ & $32,3 \mathrm{~b}$ & $0,96 \mathrm{a}$ & 0,31 & $176,4 \mathrm{c}$ \\
\hline T3 & $4,79 \mathrm{a}$ & $2,36 \mathrm{~b}$ & $37,9 \mathrm{~b}$ & $32,5 \mathrm{~b}$ & $1,13 \mathrm{a}$ & 0,34 & $187,5 \mathrm{bc}$ \\
\hline T4 & $4,29 \mathrm{a}$ & $2,36 \mathrm{~b}$ & $38,4 \mathrm{~b}$ & $33,9 \mathrm{ab}$ & $1,03 \mathrm{a}$ & 0,35 & $171,0 \mathrm{c}$ \\
\hline T5 & $4,64 \mathrm{a}$ & $2,50 \mathrm{ab}$ & $41,4 \mathrm{ab}$ & $35,4 \mathrm{ab}$ & $1,09 \mathrm{a}$ & 0,34 & $215,1 \mathrm{ab}$ \\
\hline T6 & $4,64 \mathrm{a}$ & $2,62 \mathrm{a}$ & $42,5 \mathrm{a}$ & $36,5 \mathrm{a}$ & $1,12 \mathrm{a}$ & 0,35 & $230,5 \mathrm{a}$ \\
\hline T7 & $4,57 \mathrm{a}$ & $2,62 \mathrm{a}$ & $38,5 \mathrm{~b}$ & $35,4 \mathrm{ab}$ & $1,07 \mathrm{a}$ & 0,33 & $176,4 \mathrm{c}$ \\
\hline T8 & $4,43 \mathrm{a}$ & $2,42 \mathrm{~b}$ & $41,4 \mathrm{ab}$ & $33,7 \mathrm{ab}$ & $1,06 \mathrm{a}$ & 0,37 & $184,2 \mathrm{bc}$ \\
\hline ES $\bar{x}$ & 0,13 & 0,03 & 0,90 & 0,91 & 0,04 & 0,03 & 7,50 \\
\hline
\end{tabular}

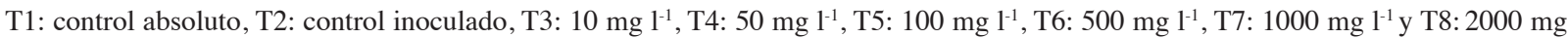
$1^{-1}$. Medias con letras iguales no difieren estadísticamente para $\mathrm{p}<0,05$, según la Prueba de Rangos Múltiples de Tukey HSD. ES X̃: Error estándar del experimento $(n=30)$. / T1: absolute control, T2: inoculated control, T3: $10 \mathrm{mg} \mathrm{l}^{-1}$, T4: $50 \mathrm{mg} \mathrm{l}^{-1}$, T5: $100 \mathrm{mg} \mathrm{1}^{-1}$, T6: 500 $\mathrm{mg} \mathrm{l}^{-1}, \mathrm{~T} 7: 1000 \mathrm{mg} \mathrm{l}^{-1} \mathrm{y} \mathrm{T}: 2000 \mathrm{mg} \mathrm{l}^{-1}$. Means with same letters do not differ statistically for $\mathrm{p}<0.05$, according to the Test of Multiple Ranges of Tukey HSD. ES $\bar{x}$ : Standard error of the experiment $(n=30)$.

El quitosano a $500 \mathrm{mg} \mathrm{l}^{-1}$ (T6), también incrementó la longitud del tallo (30\%) y radical (13\%), además del área foliar (31\%). En esta última variable también se destacó $100 \mathrm{mg} \mathrm{l}^{-1}$ (T5) con $22 \%$ de incremento. El resto de los tratamientos del polímero no difirieron de T2 y todos los tratamientos a su vez, se diferenciaron de T1, que tuvo el menor valor de área foliar (Cuadro 4). De forma general, la mejor respuesta morfoagronómica de la soya cultivada hasta la etapa de crecimiento V4 se obtuvo con la concentración $500 \mathrm{mg} \mathrm{l}^{-1}$ de quitosano (T6), cuando se adicionó con el inoculante Azofert-S ${ }^{\circledR}$ a las semillas, previo a la siembra.

\section{Discusión}

Hubo compatibilidad del quitosano en concentraciones desde 10 hasta $1000 \mathrm{mg} \mathrm{l}^{-1}$ (T3 - T8) con la cepa $B$. elkanii ICA 8001, en su aplicación conjunta sobre semillas de soya, ya que no afectaron la supervivencia de la 
bacteria. En las dos concentraciones mayores utilizadas hubo un mayor número de células viables sobre semillas en el momento cero, quizás debido a la mayor viscosidad del polímero, que permite la formación de una película sobre las semillas (Morin-Crini et al., 2019), lo que pudo mejorar la adherencia de las bacterias. Sin embargo, este efecto no se mantuvo a los 10 días de almacenadas las semillas para la concentración de $1000 \mathrm{mg} \mathrm{l}^{-1}$. Estos resultados difirieron de los obtenidos en un estudio realizado in vitro, con la misma cepa y concentraciones entre 100 y $1000 \mathrm{mg}$ $1^{-1}$ de un polímero de quitosano de $130 \mathrm{kDa}$, en el cual hubo una inhibición de la viabilidad bacteriana (Costales et al., 2016). En el estudio referido, la interacción entre las bacterias y el quitosano se determinó mediante siembra del inóculo en placas Petri que contenían medio de cultivo adicionado con las diferentes concentraciones del polímero, lo cual difirió de las condiciones del ensayo aquí realizado. Resulta más difícil para la bacteria multiplicarse en un medio de cultivo artificial con quitosano, que mantener su viabilidad al compartir con el polímero un espacio sobre semillas. Este resultado posee una gran relevancia práctica, si se tiene en cuenta que es más fácil la aplicación de ambos productos a la semilla en el momento de la siembra o previo a ella.

El almacenamiento de semillas tratadas con el inoculante y con la mezcla inoculante-quitosano redujo el número de rizobios en el tiempo. No se evaluó a partir de los diez días, ya que está demostrado que la concentración de rizobios en semillas por debajo de $10^{4}$ afecta la nodulación (Sanches-Santos et al., 2019). Es posible que la utilización de protectores bacterianos pudiera extender el tiempo de conservación de las semillas tratadas, como ha sido demostrado por otros autores (Lodeiro, 2015; O’Callaghan, 2016; Pérez-Pizá et al., 2020).

La aplicación combinada del inoculante y las distintas concentraciones de quitosano en semillas de soya, no perjudicó la nodulación de las plantas, excepto la concentración de $50 \mathrm{mg} \mathrm{l}^{-1}$ (T4), que redujo la masa seca de los nódulos formados en raíces secundarias, respecto a las plantas inoculadas. Este resultado difiere de lo encontrado por Costales et al. (2016), donde el número y la masa seca nodular, se estimularon con las concentraciones entre 10 y $100 \mathrm{mg} \mathrm{l}^{-1}$ de un polímero y oligoquitosanos adicionados al medio de crecimiento in vitro de soya.

El incremento de las variables de nodulación de plantas provenientes de semillas tratadas con la mezcla de Azofert- $S^{\circledR}$ y las concentraciones de quitosano, se debe a la compatibilidad de ambos bioestimulantes y a la efectividad del inoculante en elevar la concentración de rizobios en la semilla. El producto Azofert- $\mathrm{S}^{\circledast}$ tiene la ventaja, comparado con otros inoculantes, de contener elevadas concentraciones de factores de nodulación como señales esenciales en la interacción (Nápoles et al., 2011), lo que incide de forma positiva en la nodulación y la FBN. Esto se corroboró con el $100 \%$ de nódulos efectivos encontrado en todos los tratamientos, aunque es necesario en trabajos futuros determinar la actividad enzimática nitrogenasa para cuantificar el nitrógeno fijado en los nódulos.

Las plantas que no se inocularon, presentaron pocos nódulos, lo que demuestra la efectividad del inóculo utilizado, superior al posible efecto de bacterias residentes en el suelo empleadas afines a la soya. En una investigación se obtuvo un aumento de la nodulación, el porcentaje de nitrógeno fijado y el rendimiento de soya inoculada con una cepa comercial, respecto a cepas residentes, en suelos ácidos con bajo contenido de este mineral (Muleta et al., 2017).

En este experimento la inoculación (T2) no causó aumentos de actividad enzimática de la nitrato reductasa respecto al control (T1), mientras que solo la combinación con $500 \mathrm{mg} \mathrm{l}^{-1}$ (T6) del polímero, incrementó los valores enzimáticos en hojas de soya. Este resultado se informa por primera vez con el tratamiento de semillas con quitosano y confirma el papel estimulador en la asimilación del nitrógeno que algunos autores le atribuyen al polímero (Mondal et al., 2013; Mukhtar-Ahmed et al., 2020; Zhang et al., 2017).

La inoculación de las semillas con Bradyrhizobium aumentó, de manera general, el contenido de nutrientes en nódulos y hojas, en particular el contenido de nitrógeno en 25 y $53 \%$, respectivamente, en ambos órganos derivado en gran medida de la fijación llevada a cabo por estas bacterias. Resultados similares han sido informados en soya por Hungria et al. (2020) y Moretti et al. (2018).

Tanto la inoculación como la aplicación combinada de ambos bioestimulantes, causaron aumentos en los niveles de calcio en ambos órganos evaluados, en particular en las hojas, incrementos que fueron significativamente 
mayores con el aumento de la concentración de quitosano. Hidangmayum et al. (2019), reconocieron al quitosano como un activador de calcio que induce respuestas moleculares en las plantas, por lo que el incremento de este elemento en los órganos de soya puede vincularse con el desarrollo de las plantas y los procesos metabólicos relacionados con la morfogénesis (Fioreze et al., 2018).

Los tratamientos T7 $\left(1000 \mathrm{mg} \mathrm{l}^{-1}\right)$ y T8 $\left(2000 \mathrm{mg} \mathrm{l}^{-1}\right)$ elevaron también las concentraciones de potasio, magnesio, manganeso, cobre y cobalto en hojas, a pesar de reducir la concentración de magnesio en los nódulos, respecto a los tratamientos controles. Estos nutrientes minerales son requeridos e influyen en el desarrollo nodular, en la FBN, en el crecimiento general de las plantas y la protección del cultivo en cantidades, momentos y formas diferentes (Gao et al., 2018; Moretti et al., 2018; Weisany et al., 2013).

En el trabajo, la inoculación de las semillas y aún más su aplicación conjunta con el quitosano, redujeron la concentración de los carbohidratos totales y reductores en hojas. Este resultado es consistente con los obtenidos en un estudio de inoculación de soya con $B$. japonicum, que disminuyó la concentración de carbohidratos, respecto a las plantas que no se inocularon (Aftab et al., 2010; de-Paiva-Kérsul et al., 2019). El efecto anterior se podría atribuir a que las plantas procedentes de semillas tratadas con los bioestimulantes ejercieron un mayor consumo de estos metabolitos, respecto a las plantas no inoculadas (CA), para llevar a cabo la FBN, proceso que demanda un alto consumo de azúcares como fuente de energía para el metabolismo de los nódulos y del crecimiento (TaizaLocateli et al., 2019). La soya, para mantener estos procesos demanda entre 6 y $7 \mathrm{mg}$ de carbono por cada molécula de nitrógeno fijado (Tamagno et al., 2018).

En este trabajo todos los tratamientos presentaron valores de ambos metabolitos secundarios en el rango de los niveles informados en hojas de soya (Bellaloui, 2012). Tanto la inoculación con Bradyrhizobium, como la aplicación combinada con quitosano en las diferentes concentraciones utilizadas, excepto la mayor (T8), aumentaron los flavonoides y fenoles totales respecto al control (T2), efecto que fue más notorio con el tratamiento T3 (10 $\left.\mathrm{m} \mathrm{l}^{-1}\right)$ del polímero. Se ha informado el aumento en la acumulación de estos metabolitos mediante la aplicación de concentraciones mayores de $10 \mathrm{mg} \mathrm{l}^{-1}$ de quitosano, por imbibición de semillas y aspersión foliar en soya (Smith et al., 2017; Vargas et al., 2014) y en otras especies de plantas (Mohamed et al., 2018; Ramakrishna et al., 2017; Supapvanich et al., 2018).

La aplicación combinada del inóculo de Bradyrhizobium y el quitosano a las semillas, con los tratamientos T5 (100 mg l-1) y T6 (500 $\left.\mathrm{mg} \mathrm{l}^{-1}\right)$ del polímero, benefició el crecimiento vegetativo de la soya hasta la etapa V4, respecto a los controles (T1 y T2). Estos resultados coinciden con los obtenidos por otros autores, en el tratamiento de semillas con quitosano y bacterias promotoras del crecimiento vegetal (BPCV), donde se informó la promoción del crecimiento de plantas de maíz (Agbodjato et al., 2016) y de sorgo (Sorghum bicolor) (Kumar et al., 2019) a las concentraciones de $500 \mathrm{mg} \mathrm{l}^{-1}$ y $100 \mathrm{mg} \mathrm{l}^{-1}$, respectivamente. Estas concentraciones de quitosano también incrementaron el contenido relativo de clorofilas totales en las hojas en más de un $40 \%$ respecto al control absoluto (T1), lo cual pudiera haber beneficiado el proceso de fotosíntesis.

Un análisis integral de los resultados obtenidos en la investigación, demostró que el quitosano no ejerció efecto antimicrobiano sobre Bradyrhizobium elkanii ICA 8001, cuando se aplicó en semillas y se almacenaron hasta diez días. Sin embargo, la concentración $50 \mathrm{mg} \mathrm{l}^{-1}$ del quitosano combinada con el inóculo bacteriano, redujo el número y la masa seca de los nódulos formados en las raíces secundarias. Tanto la inoculación como su combinación con quitosano afectaron de forma positiva los contenidos de nutrientes en nódulos y hojas. El aporte de nitrógeno aumentó entre 11 y $29 \%$ en los nódulos y entre 49 y $76 \%$ en las hojas, proveniente de la fijación biológica si se toma en cuenta que la inoculación aumentó en más de ocho veces el número de nódulos y en más de siete veces su masa seca respecto a las plantas no inoculadas. A esto hay que añadir que solo se obtuvo un aumento de la actividad NR con la concentración de $500 \mathrm{mg} \mathrm{l}^{-1}$ de quitosano (T6). A su vez, la combinación inóculo-quitosano también aumentó, en dependencia de la concentración, los contenidos de nutrientes esenciales como son el calcio, manganeso, cobre y cobalto, lo que pudo jugar un papel en la señalización intracelular, la actividad de enzimas del 
metabolismo, la FBN y la fotosíntesis, todo lo cual contribuyó a un mejor crecimiento de las plantas (Ritchey et al., 2014; Weisany et al., 2013).

La inoculación del microsimbionte activó el proceso de nodulación y causó la estimulación del crecimiento de la soya al aumentar variables como el número de hojas, la masa seca aérea y el área foliar, mientras que su combinación con el quitosano, en dependencia de la concentración utilizada, estimuló en mayor medida el desarrollo del cultivo, al mejorar las variables longitud del tallo y radical, área foliar y contenido de clorofilas. Esta estimulación con el polímero pudo ocurrir al mejorarse la absorción y disponibilidad de nutrientes en la planta, que podría beneficiar también la estimulación de la actividad fotosintética y provocar una mayor formación de estructuras carbonadas, las que se utilizan en la síntesis de nuevos metabolitos que mejoran la calidad y supervivencia de las plantas. Las concentraciones de quitosano que más beneficiaron el desarrollo vegetativo de este cultivo fueron $100 \mathrm{mg} \mathrm{l}^{-1}$ (T5), $500 \mathrm{mg} \mathrm{l}^{-1}$ (T6) y $1000 \mathrm{mg} \mathrm{l}^{-1}$ (T8).

\section{Conclusiones}

La aplicación de quitosano con masa molar de $100 \mathrm{kDa}$ y concentraciones entre 10 y $1000 \mathrm{mg} \mathrm{l}^{-1}$ no inhibió la supervivencia de Bradyrhizobium elkanii sobre semillas de soya durante diez días de almacenaje.

La inoculación con Azofert- $S^{\circledast}$ estimuló la nodulación y redujo el contenido de carbohidratos solubles (totales y reductores) en hojas; su combinación con quitosano sobre semillas estimuló la actividad de la enzima nitrato reductasa, el contenido de clorofilas totales y algunos nutrientes, así como el crecimiento de las plantas de soya en la etapa vegetativa V4, en dependencia de la concentración del polímero.

\section{Referencias}

Aftab, A., Asghari, B., \& Mussarat, F. (2010). Higher soybean yield by inoculation with N-fixing and P-solubilizing bacteria. Agronomy for Sustainable Development, 30, 487-495. https://doi.org/10.1051/agro/2009041

Agbodjato, N. A., Noumavo, P. A., Adjanohoun, A., Agbessi, L., \& Baba-Moussa, L. (2016). Synergistic effects of plant growth promoting rhizobacteria and chitosan on in vitro seeds germination, greenhouse growth, and nutrient uptake of maize (Zea mays L.). Biotechnology Research International, 2016, Article 7830182. https://doi.org/10.1155/2016/7830182

Badawy, M. E. I., \& Rabea, E. I. (2011). A biopolymer chitosan and its derivatives as promising antimicrobial agents against plant pathogens and their applications in crop protection. International Journal of Carbohydrate Chemistry, 2011, Article 460381. https://doi.org/10.1155/2011/460381

Bellaloui, N. (2012). Soybean seed phenol, lignin, and isoflavones partitioning as affected by seed node position and genotype differences. Food and Nutrition Sciences, 3(4), 447-454. https://doi.org/10.4236/fns.2012.34064

Blondel, A. M., \& Blanc, D. (1975). Mise au point dúne methode de mesure in vivo de la activité de la nitrate reductase. Annals of Agronomy, 26, 309-322.

Costales, D., Falcón-Rodríguez, A. B., Nápoles, M. C., De-Winter, J., Gerbaux, P., Onderwater, R. C. A., Wattiez, R., \& Cabrera, J. C. (2016). Effect of chitosaccharides in nodulation and growth in vitro of inoculated soybean. American Journal of Plant Sciences, 7(9), 1380-1391. https://doi.org/10.4236/ajps.2016.79131

Costales-Menéndez, D., Falcón-Rodríguez, A. B., \& Travieso-Hernández, L. (2020). Efecto de la masa molecular de quitosanos en la germinación y el crecimiento in vitro de soya. Cultivos Tropicales, 41(1), Artículo e05. 
De-paiva-kérsul, P.A., Rodríguez-Torres, J. L., Orioli-Junior, V., de-Oliveira-Charlo, H. C., Menezes-de-Souza, Z., \& MirandaLemes, E. (2019). Agronomic performance of soybean inoculated and coinoculated with diazotrophic bacteria. Asian Academic Research Journal of Multidisciplinary, 6(5), 1-13.

Hemantaranjan, A., Deepmala, K., Singh, B., \& Nishant, A. (2014). A future perspective in crop protection: Chitosan and its oligosaccharides. Advances Plants \& Agriculture Research, 1(1), 23-30. https://doi.org/10.15406/apar.2014.01.00006

Fioreze, S. L., Tochetto, C., Coelho, A. E., \& Melo, H. F. (2018). Effects of calcium supply on soybean plants. Comunicata Scientiae, 9(2), 219-225. https://doi.org/10.14295/CS.v9i2.1792

Gajula, D., Verghese, M., Boateng, J., Walker, L. T., Shackelford, L., Mentreddy, S. R., \& Cedric, S. (2009). Determination of total phenolics, flavonoids and antioxidant and chemopreventive potential of basil (Ocimum basilicum L. and Ocimum tenuiflorum L.). International Journal of Cancer Research, 5(4), 130-143. https://doi.org/ 10.3923/ijcr.2009.130.143

Gao, X., Zhang, S., Zhao, X., \& Wu, Q. (2018). Potassium-induced plant resistance against soybean cyst nematode via root exudation of phenolic acids and plant pathogen-related genes. PLOS ONE, 13(7), Article e0200903. https://doi. org/10.1371/journal.pone.0200903

Hernández, J. A., Pérez, J. M., Bosch, I. D., \& Castro, S. N. (2015). Clasificación de los suelos de Cuba. Ediciones INCA.

Hidangmayum, A., Dwivedi, P., Katiyar, D., \& Hemantaranjan, A. (2019). Application of chitosan on plant responses with special reference to abiotic stress. Physiology and Molecular Biology of Plants, 25(2), 313-326. https://doi. org/10.1007/s12298-018-0633-1

Hu, Z., \& Gänzle, M. G. (2018). Challenges and opportunities related to the use of chitosan as a food preservative. Journal of Applied Microbiology, 126, 1318-1331. https://doi.org/10.1111/jam.14131

Hungria, M., Nogueira, M. A., Motta Campos, L. J., Menna, P., Brandi, F., \& Guerrero Ramos, Y. (2020). Seed pre-inoculation with Bradyrhizobium as time- optimizing option for large-scale soybean cropping systems. Agronomy Journal, 112(6), 5222-5236. https://doi.org/10.1002/agj2.20392

Hussain, I., Ahmad, S., Ullah, I., Basit, A., Ahmad, I., Sajid, M., \& Ayaz, S. (2019). Foliar application of Chitosan modulates the morphological and biochemical characteristics of tomato. Asian Journal of Agriculture and Biology, 7(3), 365-372. https://www.asianjab.com/wp-content/uploads/2019/10/5.-AJAB-2018-04-132_Okay.pdf

Kumar, S., Ye, F., Dobretsov, S., \& Dutta, J. (2019). Chitosan Nanocomposite Coatings for Food, Paints, and Water Treatment Applications. Applied Sciences, 9(12), Article 2409. https://doi.org/10.3390/app9122409

Lodeiro, A. (2015). Interrogantes en la tecnología de la inoculación de semillas de soja con Bradyrhizobium spp. Revista Argentina de Microbiología, 47(3), 261-273. http://doi.org/10.1016/j.ram.2015.06.006

Martínez, F., García, C., Gómez, L. A., Aguilar, Y., Martínez-Viera, R., Castellanos, N., \& Riverol, M. (2017). Manejo sostenible de suelos en la agricultura cubana. Agroecología, 12(1), 25-38.

Mohamed, S. A., Ahmed, H. S., \& El-Baowab, A. A. (2018). Effect of chitosan, putrescine and irrigation levels on the drought tolerance of sour orange seedlings. Egyptian Journal of Horticulture, 45(2), 257-273. https://doi.org/10.21608/ ejoh.2018.3063.1050

Mondal, M. M. A., Malek, M. A., Puteh, A. B., \& Ismail, M. R. (2013). Foliar application of chitosan on growth and yield attributes of mugbean (Vigna radiate (L.) Wilczek). Bangladesh Journal of Botany, 42, 179-183. https://doi. org/10.3329/bjb.v42i1.15910 ISSN 2215-3608 doi:10.15517/am.v32i3.44020 
Moretti, L. G., Lazarini, E., Bossolani, J. W., Parente, T. L., Caioni, S., Araujo, R. S., \& Hungria, M. (2018). Can additional inoculations increase soybean nodulation and grain yield? Agronomy Journal, 110(2), 715-721. https://doi. org/10.2134/agronj2017.09.0540

Morin-Crini, N., Lichtfouse, E., Torri, G., \& Crini, G. (2019). Fundamentals and applications of chitosan. In G. Crini \& E. Lichtfouse (eds.), Sustainable Agriculture Reviews 35 (pp. 338). Springer International. https://doi.org/10.1007/9783-030-16538-32

Mukhtar-Ahmed, K. B., Khan, M. M. A., Siddiqui, H., \& Jahan, A. (2020). Chitosan and its oligosaccharides, a promising option for sustainable crop production- a review. Carbohydrate Polymers, 227, Article 115331. https://doi.org/10.1016/j. carbpol.2019.115331

Muleta, D., Ryder, M. H., \& Denton, M. (2017). The potential for rhizobial inoculation to increase soybean grain yields on acid soils in Ethiopia. Soil Science and Plant Nutrition, 63(5), 441-451. https://doi.org/10.1080/00380768.2017.1370961

Nápoles, M. C. (Inventor). (2002, diciembre). Medio de cultivo para Bradyrhizobium japonicum. Biopreparado resultante (Patente de Cuba 2279). Ministerio de Comercio.

Nápoles, M.C., Gómez, G., Costales, D., Freixas, J. A., Guevara, E., Meira, S., González-Anta, G., \& Ferreira, A. (2011). Signals in soybeans inoculants, soybean-biochemistry, chemistry and physiology. In N. Tzi-Bun (Ed.), Soybeanbiochemistry, chemistry and physiology (pp. 323-344). InTechOpen. https://doi.org/10.5772/14882

Oniani, O. G., Chater, M., \& Mattingly, G. E. G. (1973). Some effects of fertilizers and farmyard manure on the organic phosphorus in soils. Journal of Soil Science, 24(1), 1-9.

O’Callaghan, M. (2016). Microbial inoculation of seed for improved crop performance: issues and opportunities. Applications Microbiology Biotechnology, 100, 5729-5746. http://doi.org/10.1007/s00253-016-7590-9

Paneque-Pérez, V. M, Calaña-Naranjo, J. M., Calderón-Valdés, M., Borges-Benítez, Y., Hernández-García, T. C., \& CarunchoContreras, M. (2010). Manual de técnicas analíticas para análisis de suelo, foliar, abonos orgánicos y fertilizantes químicos. Ediciones INCA.

Pérez-Pizá, M. C., Cejas, E., Zilli, C., Prevosto, L., Mancinelli, B., Santa-Cruz, D., Yannarelli, G., \& Balestrasse, K. (2020). Enhancement of soybean nodulation by seed treatment with non-thermal plasmas. Scientific Reports, 10 , Article 4917. https://doi.org/10.1038/s41598-020-61913-3

Pommeresche, R., \& Hansen, S. (2017). Examining root nodule activity on legumes (FertilCrop: Technical note) (pp. 1-4). Research Institute of Organic Agriculture FiBL, \& Norwegian Centre for Organic Agriculture. http://www.fertilcrop.net

Ponce, M., de-la-Fé, C., Ortiz, R., \& Moya, C. (2006). INCAsoy-24 e INCAsoy-27: Nuevas variedades de soya para las condiciones climáticas de Cuba. Cultivos Tropicales, 24(3), 49. https://www.redalyc.org/pdf/1932/193218163007.pdf

Prvulović, D., Malenčić, D., \& Miladinović, J. (2016). Antioxidant activity and phenolic content of soybean seeds extracts. Agro - Knowledge Journal, 17(2), 121-132. https://doi.org/10.7251/AGREN1602121P

Ramakrishna, R., Sarkar, D., Manduri, A., Iyer, S. G., \& Shetty, K. (2017). Improving phenolic bioactive-linked antihyperglycemic functions of dark germinated barley sprouts (Hordeum vulgare L.) using seed elicitation strategy. Journal of Food Science and Technology, 54(11), 3666-3678. https://doi.org/10.1007/s13197-017-2828-9

Ritchey, E. L., Lee, C., Knot, C. A., \& Grove, J. H. (2014). Soybean nutrient management in Kentucky. Agriculture and Natural Resources Publications. https://uknowledge.uky.edu/anr_reports/136 
Rouphael, Y., \& Colla, G. (2020). Biostimulants in agriculture. Frontiers Plant Sciences, 11, Article 40. https://doi.org/10.3389/ fpls.2020.00040

Sahariah, P., \& Másson, M. (2017). Antimicrobial chitosan and chitosan derivatives: a review of the structure-activity relationship. Biomacromolecules, 18(11), 3846-3868. https://doi.org/10.1021/acs.biomac.7b01058

Salachna, P., Grzeszczuk, M., \& Soból, M. (2017). Effects of chitooligosaccharide coating combined with selected ionic polymers on the stimulation of Ornithogalum saundersiae. Growth Molecules, 22, Article 1903. https://doi. org/10.3390/molecules22111903

Sanches-Santos, M., Nogueira, M. A., \& Hungria, M. (2019). Microbial inoculants: rreviewing the past, discussing the present and previewing an outstanding future for the use of beneficial bacteria in agriculture. AMB Express, 9, Article 205. https://doi.org/10.1186/s13568-019-0932-0

Sharif, R., Mujtaba, M., Ur Rahman, M., Shalmani, A., Ahmad, H., Anwar, T., \& Wang, X. (2018). The Multifunctional role of chitosan in horticultural crops: A review. Molecules, 23(4), Article 872. https://doi.org/10.3390/molecules23040872

Silva, L. R., Bento, C., Goncalves, C., Flores-Félix, J. D., Ramírez-Bahena, M. H., Peix, A., \& Velázquez, E. (2017). Legume bioactive compounds: Influence of rhizobial inoculation. AIMS Microbiology, 3(2), 267-278. https://doi.org/10.3934/ microbiol.2017.2.267

Singleton, V. L., \& Rossi, J. A. (1965). Colorimetry of total phenolics with phosphomolybdic-phosphotungstic acid reagents. American Journal of Enology and Viticulture, 16, 144-158. https://www.ajevonline.org/content/16/3/144

Smith, D. S., Gravel, V., \& Yergeau, E. (2017). Signaling in the Phytomicrobiome. Frontiers Media. https://doi.org/10.3389/9782-88945-216-3

Somogyi, M. (1952). Notes on sugar determination. Journal of Biological Chemistry, 195, 19-23. https://www.jbc.org/ content/195/1/19.full.pdf

Supapvanich, S., Chimsoontorn, V., Anan, W., Boonyaritthongchai, P., Tepsorn, R., \& Techavuthiporn, C. (2018). Effect of preharvest chitosan application on bioactive compounds of and sunflower sprouts during storage. International Journal of Agricultural Technology, 14(7), 1987-1998. http://www.ijat-aatsea.com/pdf/v14_n7_2018_\%20December/91_ IJAT_14(7)_2018_Supapvanich,\%20S..pdf

Tamagno, S., Sadras, V. O., Haegele, J. W., Armstrong, P. R., \& Ciampitti, I. A. (2018). Interplay between nitrogen fertilizer and biological nitrogen fixation in soybean: Implications on seed yield and biomass allocation. Scientific Reports, 8, Article 17502. https://doi.org/10.1038/s41598-018-35672-1

Taiza-Locateli, B., Preus da Cruz, M., Locatelli Dalacosta, N., Fuschter Oligine, K., Bertoldo, E., \& Favetti, C. I. (2019). Elicitor-induced defense response in soybean plants challenged by Bemisia tabaci. Journal of Agricultural Science, 11(2), 251-262. https://doi.org/10.5539/jas.v11n2p251

Vargas, L. I., Minchiotti, M. C., Muñoz, J. O., \& Madoery, R. R. (2014). Chitosan biopolymer and oligomer derivative as elicitors for resistance induction against pathogens in soybean (Glycine max). Journal of Chitin and Chitosan Science, 2(16), Article 1071. https://doi.org/10.1166/jcc.2014.1071

Vincent, J. M. (1970). A manual for the practical study of root-nodule bacteria. Blackwell Scientific Publishers.

Walkley, A.J. \& Black, I.A. (1934). Estimation of soil organic carbon by the chromic acid titration method. Soil Science, 37(1), 29-38. ISSN 2215-3608 doi:10.15517/am.v32i3.44020 
Weisany, W., Raei, Y. \& Allahverdipoor, K. H. (2013). Role of some of mineral nutrients in biological nitrogen fixation. Bulletin of Environment, Pharmacology and Life Sciences, 2(4), 77-84. https://www.researchgate.net/publication/262198129

Xing, K., Zhu, X., Peng, X., \& Qin, S. (2015). Chitosan antimicrobial and eliciting properties for pest control in agriculture: a review. Agronomy for Sustainable Development, 35(2), 569-588. https://doi.org/10.1007/s13593-014-0252-3

Yemm, E. \& Willis, A. J. (1954). The estimation of carbohydrate in plant extracts by Anthrone. Biochemical Journal, 57(3), 508-514. https://doi.org/10.1042/bj0570508

Yin, H., Du, Y. \& Dong, Z. (2016). Chitin oligosaccharide and chitosan oligosaccharide: Two similar but different plant elicitors. Frontiers in Plant Science, 7, Article 522. https://doi.org/10.3389/fpls.2016.00522

Zeng, D., Luo, X. \& Tu, R. (2012). Application of bioactive coatings based on chitosan for soybean seed protection. International Journal of Carbohydrate Chemistry, 2012, Article 104565. https://doi.org/10.1155/2012/104565

Zhang, X., Li, K., Xing, R., Liu, S. \& Li, P. (2017). Metabolite profiling of wheat seedlings induced by chitosan: Revelation of the enhanced carbon and nitrogen metabolism. Frontiers Plant Science, 8, Article 2017. https://doi.org/10.3389/ fpls.2017.02017 